This is a postprint of an article published by Elsevier. The final version of M. López-Pozo, F. Gasulla, J.I. García-Plazaola, B. FernándezMarín, Unraveling metabolic mechanisms behind chloroplast desiccation tolerance: Chlorophyllous fern spore as a new promising unicellular model, Plant Science, (2019), 281, 251-260 is available at https://doi.org//10.1016/j.plantsci.2018.11.012 (C) 2019 This manuscript version is made available under the CC-BY-NC-ND 4.0 license http://creativecommons.org/licenses/by-nc-nd/4.0/

\title{
Unraveling metabolic mechanisms behind chloroplast desiccation tolerance: chlorophyllous fern spore as a new promising unicellular model

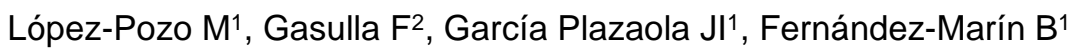

${ }^{1}$ Dpt. Plant Biology and Ecology, University of the Basque Country (UPV/EHU), Barrio Sarriena s/n, 48940 Bilbao, Spain.

${ }^{2}$ Dpto. de Ciencias de la Vida. Universidad de Alcalá, 28805 Alcalá de Henares, Madrid, Spain

\section{Abstract}

Fern spores are unicellular structures produced by the sporophyte generation that give rise to the haploid gametophyte. When released from the sporangium, spores are desiccation tolerant (DT) in the royal fern (Osmunda regalis) and contain fully developed chloroplasts. As a consequence, this type of spores is called chlorophyllous spores (CS). Upon transfer to germination conditions, CS initiate a process of imbibition that suppresses DT in $72 \mathrm{~h}$, before the germination starts. In parallel to such change in DT, thylakoids undergo a profound remodelling in composition and function. Firstly, sustained quenching of chlorophyll fluorescence is relaxed, giving rise to photochemically active CS, while lipid composition shifts from that of a resting structure to a metabolically active cell. Basically trigalactolipids decreased in favour of monogalactolipids, with a parallel desaturation of fatty acids. Storage lipids such as triacylglycerol were quickly depleted. These results highlight the importance of the structure of thylakoids lipid as a key to protect membrane integrity during desiccation, together with the saturation of fatty acids and the constitutive chlorophyll quenching to prevent oxidative damage. The CS used here, in which the same cell shifts from DT to sensitive strategy in $72 \mathrm{~h}$, reveal their potential as unicellular models for future studies on DT.

Key words: galactolipids, germination, green spores, fatty acid, nonphotochemical quenching, Osmunda, pteridophyte, photoprotection, thylakoid 


\section{Abbreviations}

A, antheraxanthin; AZ//VAZ, de-epoxidation state of the xanthophyll cycle; $\beta$-Car, $\beta$-carotene; $C$, control; Chl, chlorophyll; CS, chlorophyllous spores; DAG, diacylglycerol; DGDG, digalactosyldiacylglycerol; D, desiccation; D-H, dehydration-rehydration; DS. Desiccation sensitive; DT, desiccation tolerance; DW, dry weight; EW; equilibrium weight, FFAs, Free fatty acids; Fm, maximum chlorophyll fluorescence; Fo, minimum chlorophyll fluorescence; Fv, variable chlorophyll fluorescence; Fv/Fm, maximum photochemical efficiency of photosystem II; L, lutein; MGDG, monogalactosyldiacylglycerol; $N$, neoxanthin NPQ, non-photochemical quenching; NPQd, desiccation-induced quenching of chlorophyll fluorescence; PA, phosphatidic acid; PC, phospatidylcholine; PE, phospatidylethanolamine; PG, phosphatidylglycerol; PI, phosphatidylinositol; PL, total polar lipids; PSII, photosystem II; R, rehydration; RH, relative humidity; ROS, reactive oxygen species; SQDG, sulfoquinovosyldiacylglycerol; TAG, triacylglycerol; TeGDG, tetragalactosyldiacylglycerol; TGDG, trigalactosyldiacylglycerol; $\mathrm{V}$, violaxanthin; VAZ, violaxanthin+anteraxanthin+zeaxanthin; WC, water content; Z, zeaxanthin;

\section{Introduction}

Plant desiccation tolerance (DT) represents the ability of cells to re-establish physiological functions after drying below $0.1 \mathrm{~g} \mathrm{H}_{2} \mathrm{O} \mathrm{g} \mathrm{g}^{-1} \mathrm{DW}$ water content, or -100 MPa water potential (Alpert, 2005). This remarkable physiological strategy requires dealing with two major sources of damage linked to desiccation: mechanical and oxidative, being the latter particularly relevant in photosynthetic tissues (i.e. since photooxidation represents an additional source of injure). DT was probably essential for the water to land transition of plants (Oliver et al., 2000). In fact, DT in photosynthetic tissues is much more frequent among basal plant lineages (mosses, liverworts) than in recently evolved groups (ferns) and is very rare among angiosperms (Gaff, 1977, Poremski, 2011, Gaff and Oliver, 2013, Fernández-Marín et al., 2016, López-Pozo et al., 2018). DT of photosynthetic tissues was progressively lost in parallel to the development of efficient mechanisms to deal with drought such as cuticles, stomata and vascular tissue (Gaff and Oliver, 2013). In parallel, the evolution of land plants was also characterised by a progressive substitution of the haploid gametophyte as the dominant generation (as is the case in mosses) by the sporophyte-dominated lifecycle that occurs in seed plants. Ferns occupy an intermediate evolutionary position, with the co-existence of two independent generations: a multicellular gametophyte and a multitissular sporophyte. Fern gametophytes, resemble mosses in the sense that they lack mechanisms to prevent water losses and thus, 
are considered as poikilohydric (Kappen and Valladares 2007). On the other hand, fern sporophytes are homoiohydric (i.e. possess vascular tissue, cuticle and stomata with the exception of filmy ferns, Fam. Hymenophyllaceae, which lack stomata). Thus, to some extents, ferns summarize the evolution of land plants, and occupy an interesting intermediate phylogenetic position between mosses (with gametophyte-dominated generation and frequently DT) and angiosperms (with a sporophyte-dominated generation and only exceptionally DT).

The continuity between both fern generations occurs through the meiotic production of spores, which are released from the sporangia (in the sporophyte) and give rise to the new gametophytes. Fern spores are unicellular propagules, usually covered by a thick coat of cellulose and sporopollenin (Banks, 1999) and, frequently, DT (Ballesteros et al., 2017). The spores of some fern species (i.e.: Matteucia, Osmunda, Equisetum, Onoclea, Grammitis, Todea...) contain chlorophyll (Chl) and well-developed chloroplasts in their mature stage, these are the so-called green fern spores or, more appropriately: chlorophyllous spores (CS) (Sundue et al., 2011). It has been generally assumed that CS retain higher moisture content upon release from the sporangia and are overall more sensitive to desiccation than non-chlorophyllous fern spores (Pence, 2000). However, this distinction is not clear and recent studies have demonstrated that CS can also be remarkably DT (Ballesteros et al., 2017, 2018). As germination is generally much faster in CS than in non chlorophyllous fern spores, it has been hypothesised that the presence of chlorophyll and operative chloroplasts may represent and ecological advantage during spore germination and initial stages of gametophyte development, due to autotrophic metabolism (Pence, 2000). The payback is a risk of photooxidative damage whenever light absorption is not properly coupled to energy use (Demmig-Adams, 1990). This is typically the case of desiccated photosynthetic tissues, when $\mathrm{Chl}$ molecules continue to harvest light but carbon assimilation is completely uncoupled (Farrant, 2007). Under these conditions, the absorbed energy can potentially activate atmospheric oxygen, acting as a continuous source of reactive oxygen species (ROS) (Heber et al., 2006). In this context, fern CS that are tolerant to desiccation could be particularly vulnerable to photooxidative stress (Ballesteros et al., 2018). 
Nevertheless, photosynthetic tissues of DT plants display a complete set of photoprotection mechanisms that efficiently counteract photooxidative stress, playing thermal energy dissipation a central role among them (Heber et al., 2006, García-Plazaola et al., 2013, Fernández-Marín et al., 2016, Verhoeven et al., 2018). This mechanism consists on the reemission of the exceeded light energy as heat in the antennae complexes of the photosynthetic apparatus, and is associated with a decrease of Chl fluorescence yield, the so-called nonphotochemical quenching (NPQ). Thermal energy dissipation also relates with the de-epoxidation of the so-called xanthophyll cycle (i.e. synthesis of the carotenoids antheraxanthin (A) and zeaxanthin (Z) from violaxanthin (V)) (Demmig-Adams et al., 1995). The accumulation of zeaxanthin upon drying occurs in many taxonomically diverse DT organisms (Kranner et al., 2002, Fernández-Marín et al., 2009, 2010, 2011, 2013, 2018). Nevertheless, its relationship with desiccation-induced thermal dissipation (NPQd) is not clear and strong quenching of fluorescence independent of zeaxanthin has been described in DT-cryptogams (Bilger, 2014). All things considered, the strong and reversible quenching of chlorophyll fluorescence upon desiccation, seems to be an important protective strategy related to DT and absent in DS organisms (Bilger, 2014, Rakic et al., 2015).

In addition to dissipation of excess energy, maintenance of membrane functionality (i.e. avoidance of adjacent membrane fusion) represents another fundamental process for survival upon desiccation (Hoekstra et al., 2001). The polarity, the degree of unsaturation and the length of the fatty acid chains that constitute cell membranes, determine their biophysical properties, and thus, their capability to undergo reversible loss of water without irreparable injury to the cell (Hoekstra and Golovina, 1999). Thylakoids represent the vast majority of photosynthetic cell membranes and are mainly composed of galactolipids. Among them, mono- and di-galactosyldiacylglycerols (MGDG and DGDG, respectively) dominate in photosynthetically active membranes (Dörman, 2013). While the presence of MGDG and DGDG is essential for photosynthesis in vascular plants, it has been recently shown that their ratio to phospholipids and to oligogalactolipids (tri- and tetra: TGDG and TeGDG) declines upon dehydration in DT angiosperms (Gasulla et al., 2013). In addition, the degree of fatty acid unsaturation increases under desiccation and seems to be higher in DT 
than in DS species (Koonjul et al., 2000, Georgieva et al., 2011, Tshabuse et al., 2018).

These processes have been described in seeds or leaves of angiosperms. However, most studies on fern spores and their DT have been focused in terms of germplasm preservation, longevity and loss of viability (Mikula et al., 2015, Ballesteros et al., 2017, 2018), while the biochemical mechanisms behind DT of fern spores in general and of CS in particular are far from being understood (López-Pozo et al., 2018). We used the royal fern (Osmunda regalis L.), which produces CS able to survive low moisture content (Mikula et al., 2015), as model species. Specifically we aimed (i) to determine the extent of DT, and (ii) to underpin the physiological and biochemical mechanisms behind DT of fern CS which particular focus on photoprotection and lipid changes at thylakoid level. Additionally, and based on the fact that fern spores are frequently DT while most fern sporophytes are not (López-Pozo et al., 2018), we evaluated biochemical changes occurring in the thylakoids during the initial stages of spore imbibition and gametophyte development, and their potential relationship to the loss of DT. As recently proposed, their unicellular structure that contains the genetic information of a whole tracheophyte organism, make fern spores a very interesting model system to study multiple cellular processes such as polar differentiation and molecular networks (Suo et al., 2015), cell ageing processes (Ballesteros et al., 2017), gravity responses (Salmi et al., 2011) or cellular toxicity (Catalá et al., 2009). In this work we add a step further and propose fern CS as a unique model to study physiological and biochemical mechanisms of acquisition and or loss of tolerance to desiccation in photosynthetic organs.

\section{Materials and methods}

\subsection{Plant material}

Plant material (mature fertile fronds) was obtained in spring 2016 and 2017 from adult individuals of $O$. regalis growing in the surroundings of the University Campus (UPV/EHU, Leioa, Bizkaia, País Vasco, 4319'48.8"N 258'08.5"W).

After collection, fertile fronds were kept in laboratory at $60 \%$ relative humidity $(\mathrm{RH})$ for $24 \mathrm{~h}$ to allow the dehiscence of the sporangia and the release of the spores. The spores were then immersed in liquid $\mathrm{N}_{2}$ and stored at $-80^{\circ} \mathrm{C}$ until the 
beginning of the experiment. Before use, spores were defrosted in a water bath at $35^{\circ} \mathrm{C}$ during 5 minutes (Pence, 2008).

\subsubsection{Growing conditions for gametophytes}

Mature spores of $O$. regalis were sown in $5.5 \mathrm{~cm}$ diameter Petri plates with 10 $\mathrm{mL}$ Dyer medium (1979) (with modifications described by Quintanilla et al., 2000) solidified with agar at $1 \%$ and containing the fungicide Nystatin (100 U $\mathrm{mL}^{-1}$ ) (Sigma-Aldrich, Madrid, Spain). Plates were maintained at $20 \pm 2^{\circ} \mathrm{C}$ with $12 \mathrm{~h}$ light $/ 12 \mathrm{~h}$ dark cycles and a photosynthetic photon flux density (PPFD) of $70 \mu \mathrm{mol} \mathrm{m} \mathrm{m}^{-2} \mathrm{~s}^{-1}$ during 6 months, until fully developed gametophytes were observed. Gametophytes were carefully removed from the agar medium before starting the experiment mentioned above.

\subsection{Experimental design:}

Two different experiments were performed as follows (Fig. 1):

\subsubsection{Experiment 1: Desiccation tolerance in spores and gametophytes}

To estimate the extent of DT in spores and gametophytes and find the most appropriate $\mathrm{RH}$ to work with for the following experiments, a desiccationrehydration (D-H) cycle was performed under controlled conditions. $50 \mathrm{mg}$ of spores directly obtained from mature sporangia and nine individuals (three per treatment) of cultivated gametophytes (see below), were equilibrated during $24 \mathrm{~h}$ inside hermetically closed chambers at $80 \% \mathrm{RH}, 50 \% \mathrm{RH}$ and 10\%RH (see Fig. 1 for details). The big volume of the chambers $(3 \mathrm{~L})$, in comparison to the small amount of plant tissue, prevented $\mathrm{O}_{2}$ limitation during the incubation. Spores released from the sporangium without any desiccation treatment were considered as controls. Afterwards, rehydration was conducted by adding distilled water (1.3

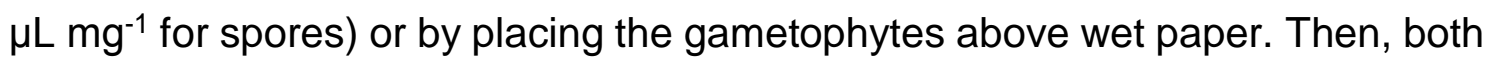
structures were maintained hydrated during $24 \mathrm{~h}$. To estimate the effects of recurrent desiccation events, a second desiccation in silica gel $(10 \% \mathrm{RH})$ was subsequently applied during $72 \mathrm{~h}$ to the spores only, due to the inability of the gametophytes to survive the first desiccation treatment (see results). Finally, a second rehydration was done with the same procedure mentioned above only for spores. All the treatments were performed in darkness. Chlorophyll fluorescence, pigments, water content (WC) and germination were measured after desiccation 
and rehydration in both cycles. The degree of DT was estimated by comparing Fv/Fm values (see details on Section 2.5.) of desiccation treatments versus controls.

\subsubsection{Experiment 2: DT loss during spore germination}

A second experiment was conducted to determine when the spores loose DT during the germination. For this, spores were placed over moistened Whatman paper (1825047, England) and kept in a growth chamber under appropriate conditions for germination (i.e.: at $100 \% \mathrm{RH}$ to prevent desiccation, at $20 \pm 2{ }^{\circ} \mathrm{C}$ and under a $12 \mathrm{~h}$ photoperiod at PPFD of $\left.70 \mu \mathrm{mol} \mathrm{m}^{-2} \mathrm{~s}^{-1}\right)$. Spores were harvested at different times during germination (12 h, 24 h, 36 h, 48 h, 72 h, 120 h and 144 h) and then desiccated over silica gel for $24 \mathrm{~h}$ in darkness. To test their viability after desiccation spores were rehydrated again with distilled water in the same Whatman paper during $24 \mathrm{~h}$ in darkness (Fig. 1). The percentage of germination and the Fv/Fm were assessed as estimators of viability after initial period of hydration (control) and after desiccation-rehydration times.

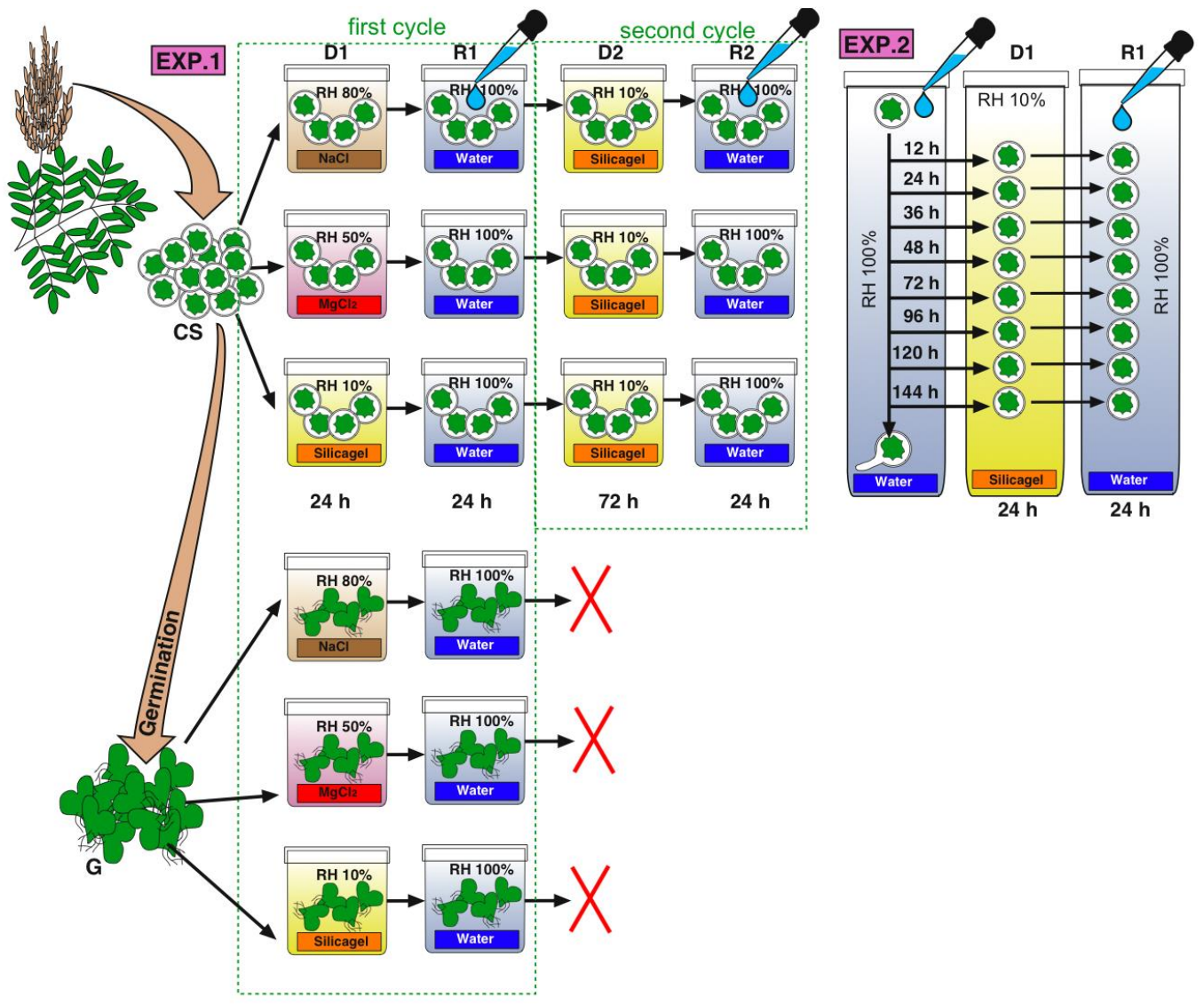

Figure1: Experimental design: Experiment 1) desiccation tolerance in spores and gametophytes and Experiment 2) loss of desiccation tolerance in spores upon germination. Desiccations and 
rehydrations were conducted in darkness, while gametophyte growth and germination of spores were conducted under $12 \mathrm{~h}$ photoperiod. First desiccation (D1), first rehydration (R1), second desiccation (D2), second rehydration (R2), relative humidity $(\mathrm{RH})$, magnesium chloride $\left(\mathrm{MgCl}_{2}\right)$, sodium chloride $(\mathrm{NaCl})$, spores $(\mathrm{S})$, gametophytes $(\mathrm{G})$ (see Methods for further details).

\subsection{Germination test}

Viability of spores before and after dehydration cycles in experiments 1 and 2 was assessed testing the percentage of germination under the same conditions used for growing gametophytes. Germination percentage was examined microscopically 20 days after sowing in 100 randomly selected spores, being expressed as percentage of germination. The criteria for considering a positive spore germination was the first emergence of the rhizoid, when the spore coat breaks (Ballesteros et al., 2011).

\subsection{Desiccation methods}

Desiccation was performed by equilibrating samples in hermetically closed chambers at three RHs. The lowest $\mathrm{RH}(10 \%)$ was achieved by equilibrating the chamber atmosphere with silica gel. Relative humidities of $80 \%$ and $50 \%$ were generated by equilibrating the atmospheres with salt solutions of $\mathrm{NaCl}$ and $\mathrm{MgCl}_{2}$, respectively.

The WC of samples was estimated as follows:

$$
W C=(E W-D W) / D W
$$

Where $\mathrm{EW}$ is the weight at the equilibrium with $\mathrm{RHs}$; DW is the weight after drying for 24-48 $\mathrm{h}$ in an oven at $70 \stackrel{\circ}{\circ}$. Samples were weighed using a balance (AB104, Mettler Toledo, Barcelona, Spain) with $0.1 \mathrm{mg}$ accuracy.

\subsection{Chlorophyll fluorescence}

Chlorophyll fluorescence was measured by two different techniques. Prior to measurements CS were always hydrated for 24 hours in darkness, so that NPQd was completely relaxed.

\subsubsection{Experiments 1}

Chlorophyll fluorescence in spores and gametophytes was measured using a Pulse Amplitude-Modulated Fluorimeter (PAM 2500, Walz, Effeltrich, Germany). 
For spores, measurements were done by entering the optical fiber inside the Eppendorf tube and for gametophytes an oblique leaf clip was used. This method allows maintaining the same distance $(15 \mathrm{~mm})$ between the optical fiber and the sample in all measurements. The minimum chlorophyll fluorescence (Fo) was determined in dark-adapted (30 $\mathrm{min}$ ) gametophytes and spores. The maximum chlorophyll fluorescence $(\mathrm{Fm})$ was induced with a saturating pulse for $500 \mathrm{~ms}$. The variable chlorophyll fluorescence $(\mathrm{Fv})$ was calculated as Fm-Fo. The ratio $\mathrm{Fv} / \mathrm{Fm}$ represents the maximum photochemical efficiency of photosystem II (PSII).

\subsubsection{Experiment 2}

To estimate the rate of recovery of individual spores the Imaging fluorescenceMicroscope was used for experiment 2, which allows measuring individual spores. Pieces of Whatman paper containing spores were placed onto a microscope slide and acclimated to darkness during 30 minutes. Measurements were made with a Microscopy Pulse Amplitude-Modulated (PAM) imaging fluorimeter (WALZ, Effeltrich, Germany), coupled to Axiostar plus microscope (Carl Zeiss, Gottingen, Germany) with WinControl program for image processing software to control the timing, settings and trigger signals for the saturating pulse light resources and special detector-ocular microscope (Fernández-Marín et al., 2012)

\subsection{Determination of photosynthetic pigments}

For analyses of chlorophylls, $\sim 15 \mathrm{mg}$ FW per replicate of plant material was used. Frozen samples were homogenized with a mortar in $1 \mathrm{~mL}$ of pure acetone solution buffered with $\mathrm{CaCO}_{3}$. The extracts were centrifuged at $13200 \mathrm{rpm}$ for 20 minutes and syringe-filtered the supernatants. Extracts were injected $(15 \mu \mathrm{L})$ in a reverse-phase Waters (Milford, MA, USA) HPLC system following the method of García-Plazaola and Becerril (1999) with the modifications described in García-Plazaola and Becerril (2001). PDA detector (Waters model 996) was used for measuring photosynthetic pigments in the range $250-700 \mathrm{~nm}$, and peaks were detected and integrated at $445 \mathrm{~nm}$ for chlorophyll content. Pigments were identified and quantified by the method described by García-Plazaola and Becerril (1999). Retention times and conversion factors for pigments were the 
same as described by García-Plazaola \& Becerril $(1999,2001)$. The deepoxidation state of the xanthophyll cycle was estimated as $(A+Z) /(V+A+Z)$ and abbreviated as AZ/VAZ.

\subsection{Lipid extraction and quantification}

Lipids for mass spectrometry were extracted according to Roughan et al., (1978) and Gasulla et al., (2013) with some modifications. Briefly, $15 \mathrm{mg}$ of freeze-dried plant material per replicate were grinded with a Mixer Mill MM 200 (Retsch, Germany) with liquid nitrogen, at a frequency of $23 \mathrm{~Hz}$, during $5 \mathrm{~min}$. A first extraction was done with $1 \mathrm{~mL}$ of $\mathrm{CHCl}_{3}: \mathrm{MeOH}(1: 2, \mathrm{v} / \mathrm{v})$ and the organic phase collected. The lipid extraction was repeated two times with $1 \mathrm{~mL} \mathrm{CHCl} 3: \mathrm{MeOH}$ $(2: 1, \mathrm{v} / \mathrm{v})$ and the organic phases were combined. One volume of $\mathrm{CHCl}_{3}$ and 0.75 volumes of aqueous $300 \mathrm{mM}$ ammonium acetate were added to the combined chloroform extracts. Samples were vortexed and centrifuged (2000 g, $5 \mathrm{~min}$ ). The organic phase was harvested. The solvent of the lipid extract was evaporated under a stream of $\mathrm{N}_{2}$. Total lipids were dissolved in $1 \mathrm{~mL}$ of $\mathrm{CHCl}_{3} / \mathrm{MeOH}(2: 1$, $\mathrm{v} / \mathrm{v}$ ), divided into two $500 \mu \mathrm{L}$ aliquots and concentrated again by evaporation. Solid phase extraction of complex lipid extract on silica column and lipid quantification by Q-TOF MS/MS measurements was carried out according to Gasulla et al., (2013).

\subsection{Statistical analysis}

Kolmogorov-Smirnov and Levene tests were used respectively to check for normal distribution and homogeneity of variance of the data. One-way analysis of variance (ANOVA), with Tukey as post-hoc, was used to check for significant differences among treatments. For non-normal data, Kruskal-Wallis test was applied. Statistical differences were considered at $p<0.05$. All analyses were performed using the SPSS 17.0 statistical package.

\section{Results}

\subsection{Exp 1: Desiccation tolerance in spores and gametophytes}

Tolerance to desiccation at three different RHs of spores and gametophytes of $O$. regalis was estimated by measuring $\mathrm{Fv} / \mathrm{Fm}$ (Fig. 2a,b). Spores equilibrated at 
80 and $50 \% \mathrm{RH}$ during $24 \mathrm{~h}$ did not show differences on Fv/Fm respect to control, whereas at $10 \% \mathrm{RH} \mathrm{Fv} / \mathrm{Fm}$ was significantly lower than the rest (Fig. 2a). On the other hand, gametophytes did not recover control values $(0.515 \pm 0.014)$ after any desiccation treatments at any $\mathrm{RH}$ (Fig. 2b), with no differences between treatments. Thus, the spores, but not the gametophytes, were able to recover from desiccation. Consequently, a second cycle of desiccation was conducted in spores only, at the most severe condition $(10 \% \mathrm{RH})$, to evaluate the effect of recurrent desiccation cycles as it may happen in nature.

After second dehydration (D2), recovery of Fv/Fm fell significantly in all spores, accentuating differences among treatments. When all spores were kept in $10 \% \mathrm{RH}$, those previously exposed to the stronger desiccation $(10 \% \mathrm{RH})$ showed the highest decline in $\mathrm{Fv} / \mathrm{Fm}$ and germination percentage $(0.378 \pm 0.147$ and $41.49 \pm 2.77 \%$, respectively), although maintained the highest WC after this second desiccation. Thus, the lower $\mathrm{RH}$ was in $\mathrm{D} 1$, the worse was the recovery of Fv/Fm after D2.

Water content (WC) of spores equilibrated at $80 \% \mathrm{RH}$ during $24 \mathrm{~h}$ was very similar to that of spores in their sporangial state, this is, control values (Fig. 2c). Thus, after 24 hours of desiccation under different $\mathrm{RHs}$, WC decreased only in those spores exposed to $50 \% \mathrm{RH}$ and $10 \% \mathrm{RH}$, reaching a final WC of $0.117 \pm 0.007$ and $0.110 \pm 0.020 \mathrm{gH}_{2} \mathrm{O} \mathrm{g}{ }^{-1} \mathrm{DW}$, respectively. When the spores equilibrated at $80 \% \mathrm{RH}$ and $50 \% \mathrm{RH}$ during $\mathrm{D} 1$ were exposed to $\mathrm{D} 2, \mathrm{WC}$ values were even lower than after the first cycle. Interestingly, this was not the case of spores desiccated twice at $10 \% \mathrm{RH}$ in silica gel, which presented the highest WC (Fig. 2c). In spite of the significant differences in WC between desiccation treatments, the $\mathrm{Fv} / \mathrm{Fm}$ recovery did not show the same differences in mature spores.

Germination rate as a second estimate of spore viability did not decrease significantly after D1, regardless the final WC (Fig. 2d). Thus, this first desiccation process did not affect the germination percentage of mature spores or the $\mathrm{Fv} / \mathrm{Fm}$ recovery (except for the 10\%RH treatment) (Fig. 2a, c). Germination percentage showed the same tendency as Fv/Fm recovery data (Fig. 2a, d). 

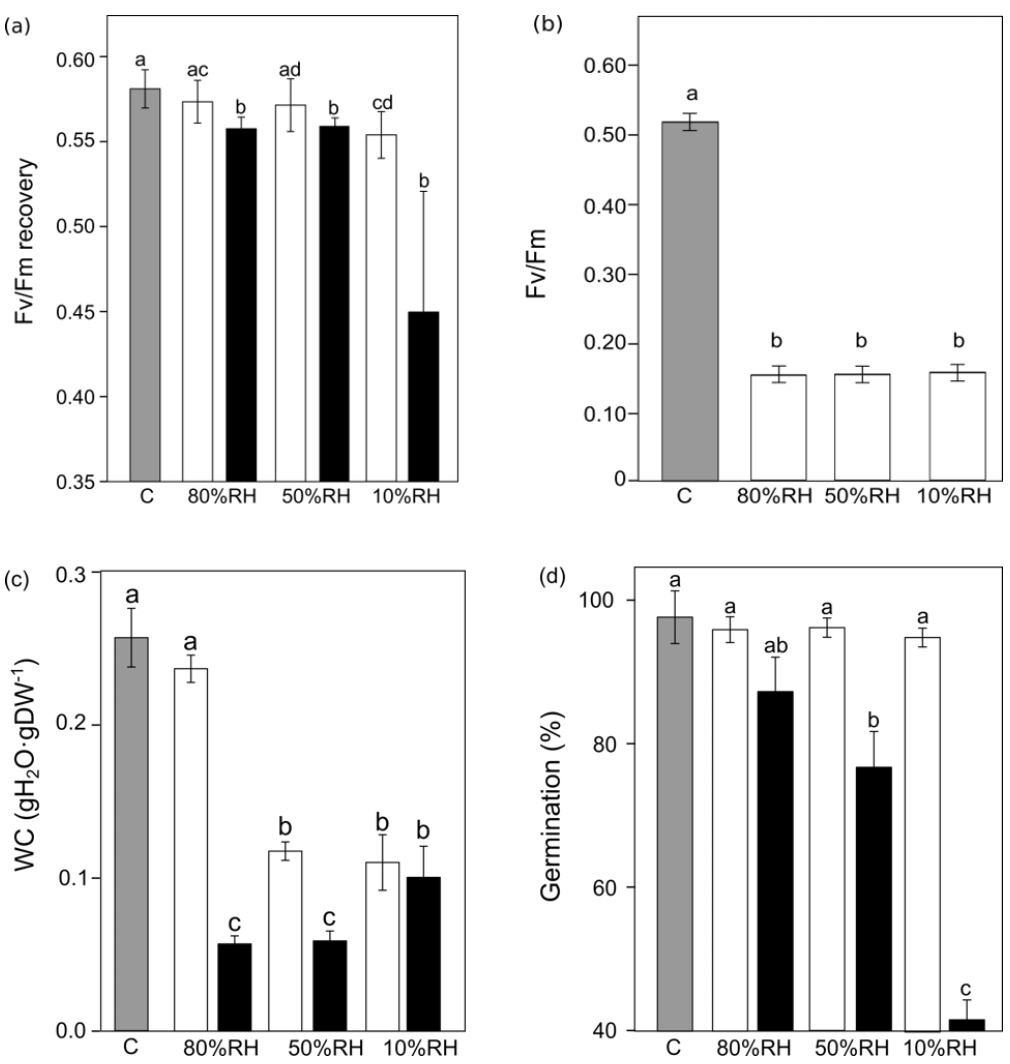

Figure 2: Estimation of tolerance to desiccation in spores and gametophytes of $O$. regalis. (a and b) maximum photochemical efficiency of PSII (Fv/Fm) spores and gametophytes respectively; (c) water content (WC), and (d) germination percentage of spores. The WC was measured after desiccation. The $\mathrm{Fv} / \mathrm{Fm}$ values were obtained after rehydration: $24 \mathrm{~h}$ of incubation under wet and dark conditions. Germination was estimated after 20 days of incubation under wet and $12 \mathrm{~h}$ photoperiod. Two desiccation/rehydration cycles were performed in spores. First desiccation was performed at the indicated $\mathrm{RH}$ s while second desiccation was performed at $10 \% \mathrm{RH}$ in all sample sets. Control values are indicated in grey bars. Measurements after first desiccation treatment (white bars) and after second desiccation (black bars) are shown. Each bar represents the mean $\pm S E$ ( $n=5$ for spores and $n=3$ for gametophytes). Different letters within each panel indicate significant differences among treatments $(P<0.05)$.

In parallel with the above mentioned changes in Fv/Fm of spores, the minimal fluorescence (Fo) changed dramatically during the course of the desiccation and rehydration treatments (Fig. 3). Thus, during the first desiccation, Fo was quenched with no significant differences among treatments and control values of spores. Similarly, Fo increased again in the first hydrated state, without differences between RHs. However, during the second desiccation Fo of the spores previously desiccated at $10 \% \mathrm{RH}$ was not quenched to the same extent as the other treatments (Fig. 3). Notice the significant differences between D1 
and D2 in panel (c), while no significant differences are found between D1 and D2 in panels (a) and (b).
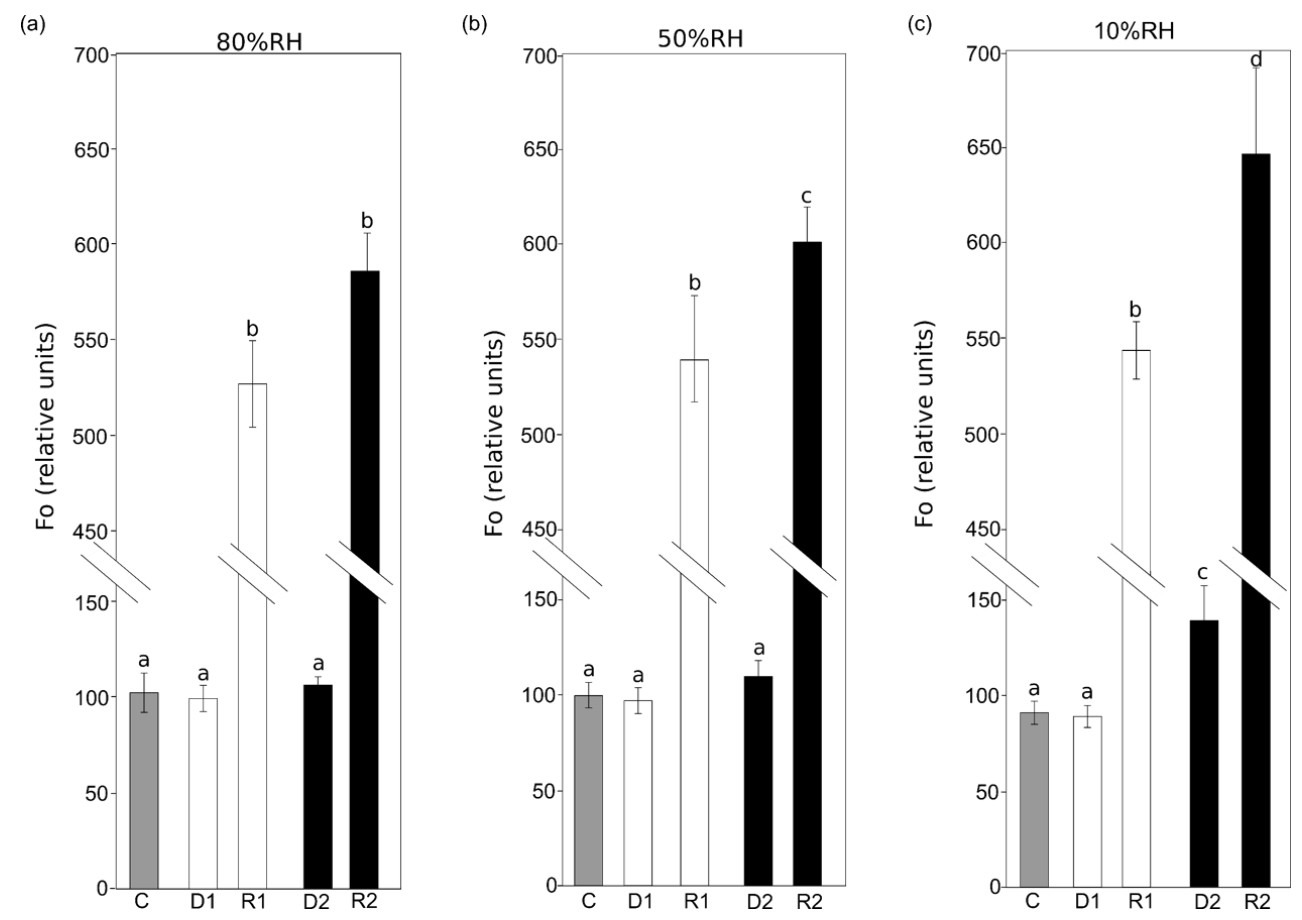

Figure 3: Fo of $O$. regalis spores at different points during two consecutive desiccation-rehydration cycles under different $\mathrm{RHs}$. First desiccation was performed at the indicated $\mathrm{RHs}$ ( $80 \%$ in panel (a), $50 \%$ in panel (b) and $10 \%$ in panel (c)) while second desiccation was performed at $10 \% \mathrm{RH}$ in all sample sets. Grey bars represent Fo control values (C). White bars represent Fo after first desiccation (D1) and rehydration (R1). Black bars represent Fo after second desiccation (D2) and rehydration $(R 2)$. Each bar represents the mean $\pm S E(n=5)$. Different letters indicate significant differences among treatments $(P<0.05)$.

To evaluate whether fluorescence quenching was related with the operation of the xanthophyll cycle, the de-epoxidation state (AZ/VAZ) was assessed (Fig 4). Mature spores, in the control stage, showed an elevated AZ/VAZ ratio $0.597 \pm$ 0.003 (Fig. 4). During desiccation treatments, no further de-epoxidation was induced in neither D1 or D2. Indeed, AZ/VAZ decreased in the subsequent cycles of dehydration-hydration performed in darkness, regardless of the extent of desiccation (Fig. 4, compare panels a, b and c.) 

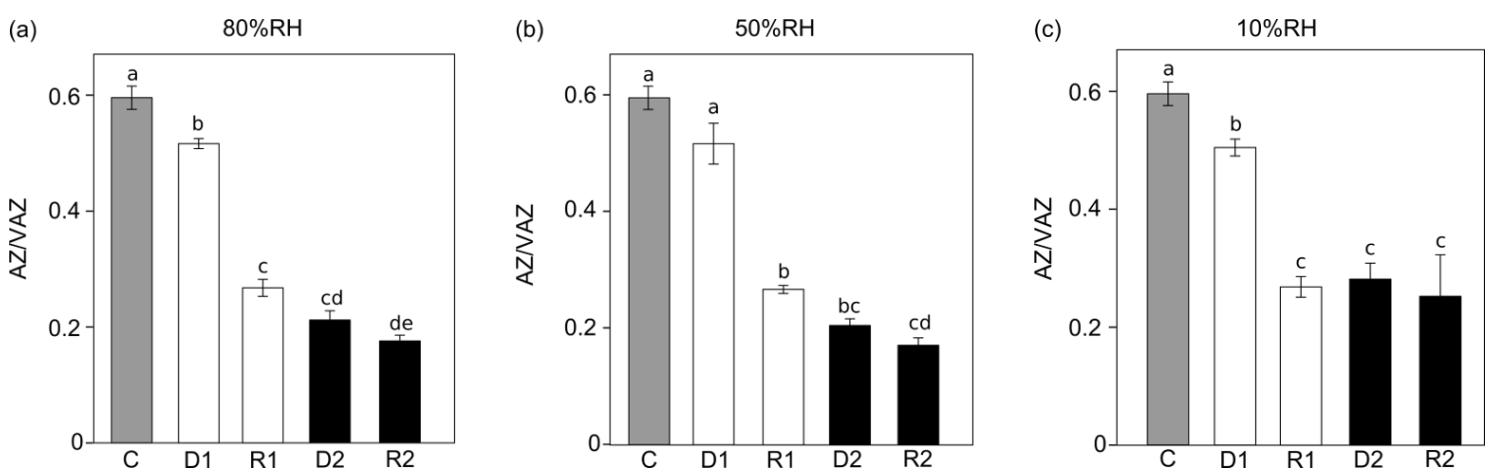

Figure 4: AZ/VAZ of O.regalis spores at different points during two consecutive desiccationrehydration cycles under different RHs. Grey bars represent AZ/VAZ control values (C). White bars represent AZ/VAZ after first desiccation (D1) and rehydration (R1). Black bars represent AZ/VAZ after second desiccation (D2) and rehydration (R2). Each bar represents the mean \pm SE $(n=5)$. Different letters indicate significant differences between treatments $(P<0.05)$.

Photosynthetic pigment composition was compared in spores and gametophytes of $O$. regalis (Table 1 ). Both generations contained the same six major carotenoids (neoxanthin, violaxanthin, antheraxanthin, lutein, zeaxanthin and $\beta$ carotene) but their ratios to chlorophyll were significantly higher in the gametophyte. The relative proportions among some carotenoids also differed. Thus, the de-epoxidation level of xanthophyll cycle (AZ/VAZ) was higher in spores compared with gametophytes. The ratio $\mathrm{Chl}$ a/b was slightly, but significantly lower, in gametophytes than in spores (mean \pm SE, Table1). 


\section{Table1}

Pigment composition ( $\mathrm{mmol} \mathrm{mol}{ }^{-1} \mathrm{Chl}$ ) of mature spores of $O$. regalis in the control state $(\mathrm{C})$ (nonmanipulated) and of the 6 -month old gametophyte $(G)$. Values represent the mean $\pm S E(n=5)$. Neoxanthin $(\mathrm{N})$, violaxanthin $(\mathrm{V})$, antheraxanthin $(\mathrm{A})$, lutein $(\mathrm{L})$, zeaxanthin $(\mathrm{Z}), \beta$-carotene $(\beta$ $\mathrm{Car}$ ), chlorophyll $\mathrm{a} / \mathrm{b}$ ratio $(\mathrm{Chl} \mathrm{a} / \mathrm{b})$. Values in the same row line with different letters are significantly different $(P<0.05)$. Values are means $\pm S E(n=5)$.

\begin{tabular}{lll}
\hline & \multicolumn{1}{c}{$\mathbf{S}$} & \multicolumn{1}{c}{$\mathbf{G}$} \\
\hline $\mathbf{N}$ & $45.2 \pm 0.6 \mathrm{a}$ & $54.0 \pm 1.4 \mathrm{~b}$ \\
$\mathbf{V}$ & $21.0 \pm 0.4 \mathrm{a}$ & $30.2 \pm 0.5 \mathrm{~b}$ \\
$\mathbf{A}$ & $7.5 \pm 0.2 \mathrm{a}$ & $5.2 \pm 0.2 \mathrm{~b}$ \\
$\mathbf{L}$ & $203.4 \pm 1.9 \mathrm{a}$ & $118.9 \pm 2.5 \mathrm{~b}$ \\
$\mathbf{Z}$ & $23.5 \pm 0.5 \mathrm{a}$ & $9.6 \pm 0.3 \mathrm{~b}$ \\
$\mathbf{\beta}-\mathbf{C}$ & $54.8 \pm 2.5 \mathrm{a}$ & $62.4 \pm 0.6 \mathrm{~b}$ \\
$\mathbf{V A Z}$ & $52.1 \pm 0.8 \mathrm{a}$ & $45.0 \pm 0.6 \mathrm{~b}$ \\
$\mathbf{C h l} \mathbf{a} / \mathbf{b}$ & $3.1 \pm 0.0 \mathrm{a}$ & $2.2 \pm 0.0 \mathrm{~b}$ \\
AZ/VAZ & $0.6 \pm 0.0 \mathrm{a}$ & $0.3 \pm 0.0 \mathrm{~b}$
\end{tabular}

\subsection{Exp 2: DT loss during spore germination}

Based on the observation that the spores are DT but not the gametophyte that is formed after germination, it is obvious that the ability of surviving water loss, has to disappear at some point of this development. With the aim to determine when this capacity is lost, and which major changes in thylakoid membranes are associated to it, spores were incubated under germination conditions (to trigger germination and initial stages of gametophyte development) and their capability to withstand desiccation was assessed at different times during $144 \mathrm{~h}$. The response to a cycle of desiccation and rehydration of $\mathrm{Fv} / \mathrm{Fm}$ and germination percentage along time (Figure 5) showed that spores of $O$. regalis became sensitive to desiccation $72 \mathrm{~h}$ after incubation under germination conditions (e.g. at this time point: no spore was able to germinate after a desiccation treatment). Thus, 3 days of illumination and imbibition was the shortest time needed for loss of DT in $100 \%$ of $O$. regalis spores. No recovery after desiccation was possible beyond this time point (e.g. at $\geq 3$ d, Fig. 5). 


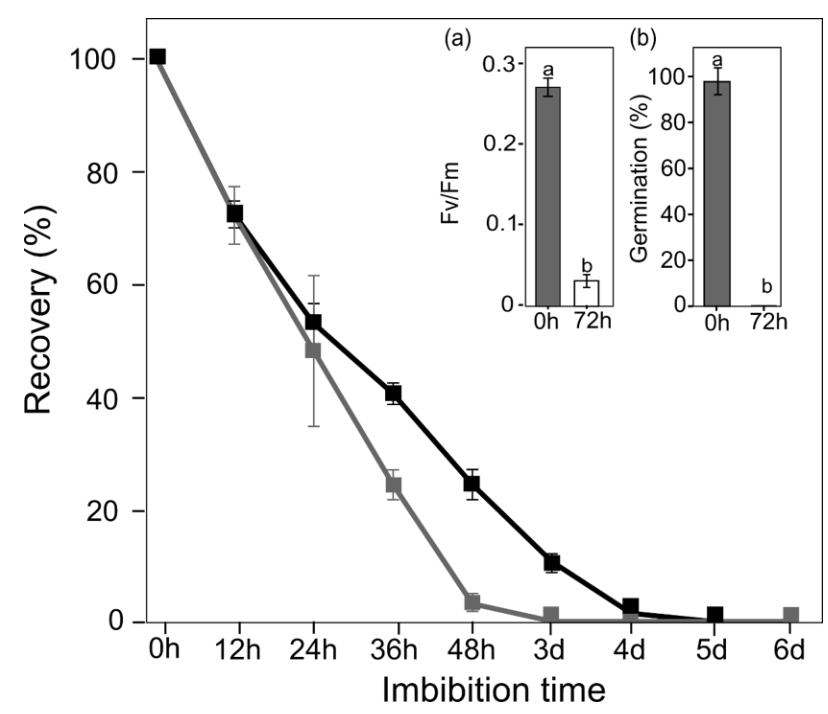

Figure 5: Fv/Fm recovery percentage (black line) and germination percentage (grey line) after a cycle of desiccation and rehydration in spores exposed for various times to germinating conditions (hydrated and illuminated) during 6 days. Fv/Fm (a) and germination percentage (b) after 72h of light and hydration. Control and recovery values. Each bar represents the mean $\pm S E(n=3)$. Different letters indicate significant differences between treatments $(P<0.05)$.

To study whether changes in chloroplast lipid composition were related with DT, it was characterized in gametophytes and spores before and after DT loss. Total lipid amount, and composition varied greatly during germination of the spore and gametophyte development (Fig. 6). The content of TAG, the most abundant lipid (120 $\mathrm{nmol} \mathrm{mg}^{-1} \mathrm{DW}$ ), decreased about $30 \%$ after three days of germination and gametophytes only had $6 \%$ of the initial amount. The analysis of TAG by Q-TOF MS/MS showed that 52:x (16:x/18:x/18:x) and 54:x (18:x/18:x/18:x) were the most abundant molecular species in the spores, after hydration the amount of all of them started to decrease (Fig. S1). The absolute content of DAG increased from $7.9 \mathrm{nmol} \mathrm{mg}^{-1} \mathrm{DW}$ in the spores to $16.9 \mathrm{nmol} \mathrm{mg}^{-1} \mathrm{DW} 72 \mathrm{~h}$ after hydration, decreasing to $13.6 \mathrm{nmol} \mathrm{mg}^{-1} \mathrm{DW}$ in the gametophyes (Fig. 6A). The slight accumulation of DAG was due to a raise in the proportion of $34: x(16: x / 18: x)$ and 36:x (18:x/18:x) molecular species (Figure S1), which might be the result of the early TAG degradation. The total amount of polar lipids showed a $20 \%$ raise, from 74.5 to $89.5 \mathrm{nmol} \mathrm{mg-1} \mathrm{DW}$, after $72 \mathrm{~h}$ of hydration, and returned to spore levels in the gametophytes (Fig. 6a, b).

Regarding galactolipids, the percentage of MGDG in relation to total polar lipids increased from $35 \%$ in spores to $43 \%$ in hydrated spores and $47 \%$ in 
gametophytes, whereas the percentage of DGDG remained constant around 24 $\%$ (Figure 6b). On the contrary, the amount of TGDG decreased rapidly during the first three days of germination, from 1.2 to $0.6 \%$ (Figure $6 \mathrm{~d}$ ), its presence was residual in the $O$. regalis gametophyte.

The most abundant phospholipid in $O$. regalis spores was $\mathrm{PC}$, representing the $14 \%$ of total polar lipids, during germination it decreased to $12 \%$, dropping to 8 $\%$ in gametophytes (Fig. 6b). The proportion of $\mathrm{PI}$ also decayed significantly after $72 \mathrm{~h}$ of hydration, from $9 \%$ to $5 \%$, and in gametophytes the proportion of PI declined to $3 \%$ (Fig. 6b). The amount of PE was reduced $40 \%$ in gametophytes respect to dried and hydrated spores (Fig. 6c). In these three phospholipids, the decreased was due to a decay in 34:x molecular species, 34:2 in PE and PI, and $34: 3$ in PC (Fig. S2 and S3). The percentage of PG remained constant during germination and gametophyte development (Fig. 6c). The only phospholipid which concentration increased was PA, its concentration was about two-fold higher in hydrated spores and gametophytes than in dried spores (Fig. 6c). The percentages of the different PA molecular species remained constant indicating that the increase in PA was caused by the accumulation of all molecular species. Finally, the proportion of SQDG did not change during $O$. regalis germination and gametophyte development (Fig. 6b). 

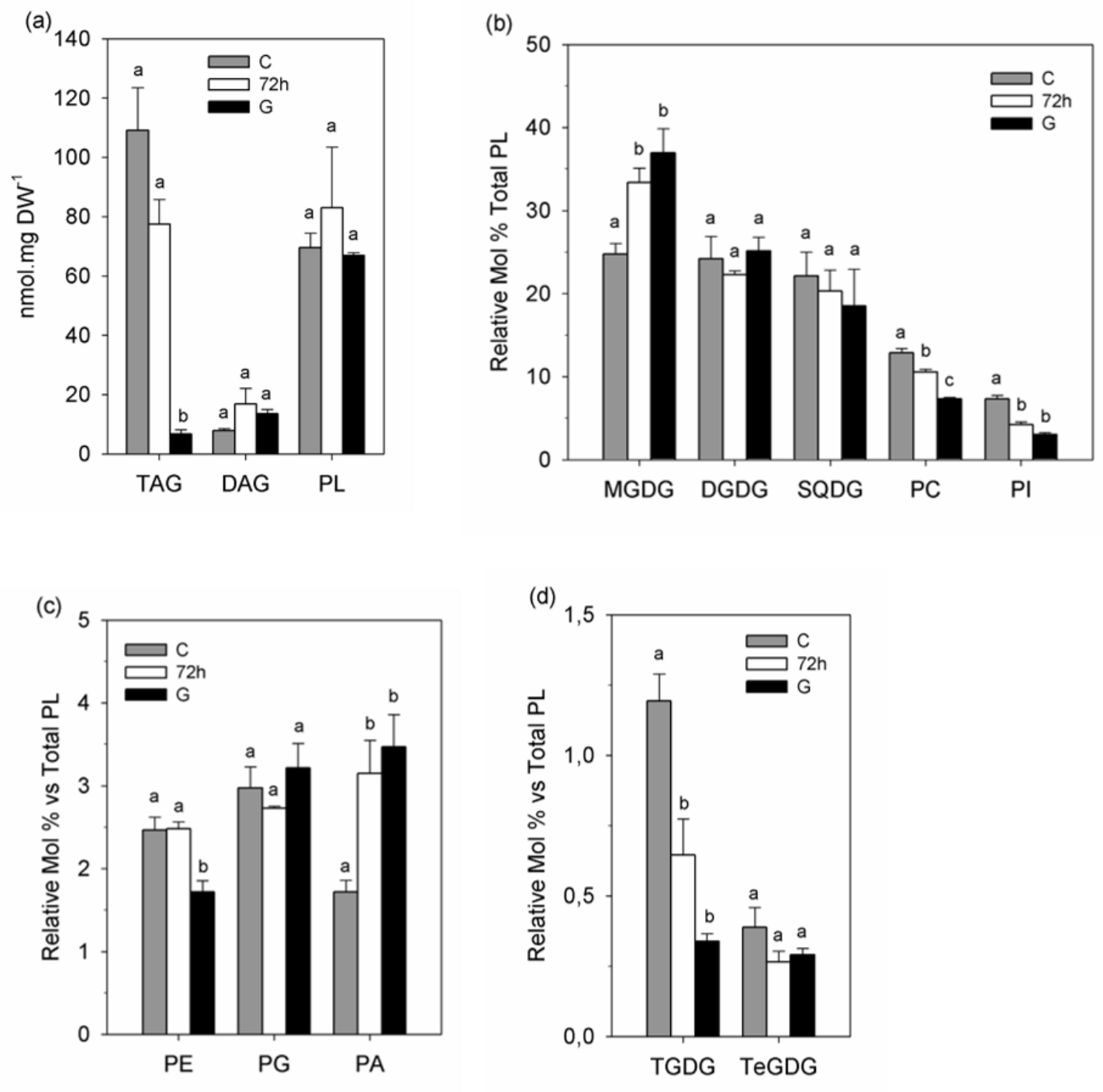

Figure 6. Changes in lipid composition during germination and development of Osmunda regalis: C) control values; 72h) spores after 3 days of light and hydration; G) 6 months gametophyte. (a) Amounts of the neutral lipids (TAG and DAG) and total polar lipids are expressed in nanomols per milligram of dry weight (a). Major (b), minor polar lipid (c) and oligogalactolipids (d) expressed as molar percentage relative to the total polar lipid amount. DW, dry weight. DAG, diacylglycerol; DGDG, digalactosyldiacylglycerol; MGDG, monogalactosyldiacylglycerol; PA, phosphatidic acid; PC, phospatidylcholine; PE, phospatidylethanolamine; PG, phosphatidylglycerol; PI, phosphatidylinositol; PL, total polar lipids; SQDG, sulfoquinovosyldiacylglycerol; TAG, triacylglycerol; TeGDG, tetragalactosyldiacylglycerol; TGDG, trigalactosyldiacylglycerol. Values in the same row line with different letters are significantly different $(P<0.05)$. Values are means $\pm \operatorname{SE}(n=3)$.

The analysis of the molecular species of each glycolipid showed that there was a general replacement of low unsaturated by high unsaturated phospholipids and galactolipids during germination and, specially, in the gametophytes (Fig. S2 and 
S3). The calculation of the double bound index (DBI) confirmed this observation (Table 2). The degree of unsaturation was higher in all phospholipids and galactolipids, with the exception of TGDG and TeGDG, which abundance was negligible in the gametophytes. In average, the DBI of polar lipids was $35 \%$ higher in the gametophytes than in the spores. For neutral lipids, the unsaturation level remained constant in TAG, while the DBI decreased in DAG, being $30 \%$ lower in gametophytes than in spores.

Table 2. Double bond index (DBI) of Osmunda regalis lipids in the initial control state $(C)$, in spores after $72 \mathrm{~h}$ of light and hydration (72h) and in 6 months gametophytes $(\mathrm{G}) . \mathrm{DBI}=(\Sigma[\mathrm{N} \times$ mol\% lipid])/2, where $\mathrm{N}$ is the total number of double bonds in the two fatty acid chains of each glycerolipid molecule. Values in the same row line with different letters are significantly different $(P<0.05)$. Values are means $\pm S E(n=3)$.

\begin{tabular}{lccc}
\hline & $\mathbf{C}$ & $\mathbf{7 2 h}$ & $\mathbf{G}$ \\
\hline MGDG & $240.3 \pm 1.8 \mathrm{a}$ & $235.7 \pm 0.5 \mathrm{a}$ & $312.9 \pm 26.4 \mathrm{~b}$ \\
DGDG & $177.9 \pm 10.1 \mathrm{a}$ & $189.6 \pm 3.6 \mathrm{a}$ & $220.2 \pm 3.6 \mathrm{~b}$ \\
SQDG & $155.0 \pm 1.4 \mathrm{a}$ & $165.1 \pm 9.3 \mathrm{ab}$ & $198.6 \pm 13.9 \mathrm{~b}$ \\
PC & $156.4 \pm 0.2 \mathrm{a}$ & $158.8 \pm 0.8 \mathrm{a}$ & $200.8 \pm 4.3 \mathrm{~b}$ \\
PI & $120.9 \pm 2.0 \mathrm{a}$ & $107.9 \pm 1.3 \mathrm{a}$ & $142.9 \pm 1.6 \mathrm{a}$ \\
TGDG & $229.4 \pm 1.2 \mathrm{a}$ & $218.2 \pm 3.4 \mathrm{~b}$ & $225.2 \pm 3.6 \mathrm{ab}$ \\
TeGDG & $229.6 \pm 3.7 \mathrm{a}$ & $226.1 \pm 3.9 \mathrm{a}$ & $226.7 \pm 3.4 \mathrm{a}$ \\
PE & $156.4 \pm 0.2 \mathrm{a}$ & $158.8 \pm 0.8 \mathrm{a}$ & $200.8 \pm 4.3 \mathrm{~b}$ \\
PG & $115.6 \pm 0.9 \mathrm{a}$ & $114.2 \pm 3.6 \mathrm{a}$ & $161.7 \pm 16.9 \mathrm{~b}$ \\
PA & $167.2 \pm 1.5 \mathrm{ab}$ & $156.0 \pm 3.9 \mathrm{a}$ & $170.8 \pm 3.9 \mathrm{~b}$ \\
PL & $180.1 \pm 3.1 \mathrm{a}$ & $189.5 \pm 4.0 \mathrm{a}$ & $243.3 \pm 11.0 \mathrm{~b}$ \\
TAG & $140.7 \pm 2.7 \mathrm{a}$ & $145.7 \pm 1.0 \mathrm{a}$ & $166.5 \pm 26.3 \mathrm{a}$ \\
DAG & $191.1 \pm 4.1 \mathrm{c}$ & $156.7 \pm 9.3 \mathrm{~b}$ & $130.6 \pm 1.9 \mathrm{a}$ \\
\hline
\end{tabular}

\section{Discussion}

Pteridophytes occupy a key evolutionary position between bryophytes and angiosperms, showing an intermediate DT behavior (Oliver et al., 2000). Thus, while bryophytes are considered "fully" DT plants, angiosperms are referred to as "modified" DT plants (Oliver et al., 2000) with ferns showing characteristics of both groups. In addition, both DS and DT generations are observed in their life cycle, as a mixture between vascular and non-vascular plants (Farrar et al., 2008). Thus, DT is considered to be common in fern gametophytes whereas the sporophyte is DT only in 10\% of species (López-Pozo et al., 2018). Additionally, 
ferns produce unicellular spores, which are DT in most, but not all, species (López-Pozo et al., 2018). Then, they represent an excellent model to understand the mechanisms that allow plants to be DT. The species studied here, O. regalis, produces chlorophyllous spores that are DT but give rise to a DS gametophyte. This implies that, at a certain point of development, DT has to be lost. Overall, the spores of $O$. regalis represent a unique opportunity for the study of physiological processes behind the loss of DT in photosynthetic tissues.

The occurrence of DT within tracheophytes is widespread in reproductive structures, including non-green spores, while in vegetative tissues is much more uncommon (Bewley and Krochko 1982, Oliver and Bewley 1997). This is probably because chloroplasts are the main source of reactive oxygen species (ROS) upon desiccation, as light energy absorbed by chlorophyll greatly exceeds the capacity for photosynthetic use, leading to an unavoidable oxidative damage (Smirnoff, 1993). In the case of $O$. regalis, spore pigment composition was qualitatively undistinguishable from that of angiosperm leaves. In fact, the Chla/b ratio in spores was closer to that of tracheophytes (Esteban et al 2015) than in the gametophyte, which it resembled that of bryophytes (Table 1) (Marschall and Proctor 2004). When mature and hydrated, these spores were able to activate photochemical processes as shown by Fv/Fm values (Table 1, Fig. 2) which is in agreement with well-developed chloroplasts shown in other Osmunda species (O. japonica, O. cinnamomea, Takano and Inoue, 1992, Suo et al., 2015).

Mature spores of $O$. regalis behaved as DT photosynthetic organs, since they were able to recover Fv/Fm after D-H cycles in which the WC (in \% to DW) fell bellow $10 \%$ (Fig 2). Not only the final water content, but also the drying speed, influence the recovery of photosynthesis, being generally fast drying more damaging (Proctor, 2003; Gasulla et al., 2009; Pressel and Duckett, 2010; Stark 2017). This is probably the reason for the reduced recovery when the spores were dried at the lowest $\mathrm{RH}(10 \%)$, and for the greater decrease on photochemical efficiency of PS II after the second D (Fig. 2). Interestingly, Fv/Fm recovery values correlated with germination percentage of spores (data not shown), which suggests $\mathrm{Fv} / \mathrm{Fm}$ as a potential non-invasive marker of spore viability. This could represent an additional interesting advantage for monitoring of fern CS during storage, as it would avoid unnecessary use of samples for germination tests. 
DT organisms possess a set of physiological tools to limit oxidative risk due to desiccation. One of the most widespread among DT organisms is a kind of sustained thermal dissipation of excess energy that results on a desiccationinduced quenching of chlorophyll fluorescence (NPQd) (Bilger, 2014). This mechanism has been reported in bryophytes, algae, cyanobacteria and lichens (Bilger, 2014), and until now was suggested to be absent in DT tracheophytes (Georgieva et al., 2005). The NPQd mechanism consist in a strong decline in Fo in those DT organisms, whereas in DS Fo increases upon desiccation probably due to injury in PSII (Bilger, 2014). Our results with O. regalis spores, though, have revealed its occurrence in ferns too (Fig. 3). Interestingly, when the survival was affected by desiccation, the capacity of Fo quenching was lower (Figs 2, 3). In this study, the almost complete quenching of Fo that takes place upon drying in green spores of $O$. regalis, supports the activation of NPQd probably playing a fundamental role in the dissipation of light that, in absence of water, is always excessive (Fig 3). In agreement with such strong photoprotection capacity, the AZ/VAZ ratio is considerably higher in spores before hydrating them for the first time than in non-stressed vascular plants (Demmig-Adams, 1990). Although the presence of $Z$ is not a prerequisite to the NPQd as shown by Herber et al., (2010) in experiments in which its formation was inhibited, it has been demonstrated that Z contributes by NPQ-independent mechanisms to decrease the damaging effects of desiccation (Fernández-Marín et al., 2013). Similarly, O. regalis spores activated NPQd without $Z$ accumulation (Fig 4). Very likely the free fraction of $Z$ molecules located within the thylakoid membrane (and not directly associated with photosynthetic protein complexes) play key roles in the stabilization and antioxidant protection of the photosynthetic membranes (Havaux and GarcíaPlazaola, 2014; Dall'Osto et al., 2010).

One of the most remarkable physiological changes described in this work is the loss of DT occurred within a single cell (i.e. CS of $O$. regalis) in the impressively fast of $72 \mathrm{~h}$ during imbibition. (Individual spore lost DT in 12 hours but if we understand the spores as a population, after 12 hours, the $75 \%$ of the population remains DT that is why we used the time $72 \mathrm{~h}$, where almost all the population is DS). Taking advantage of such a fast transition lipid composition was assessed before and after the DT-loss in $O$. regalis spores and in gametophytes too. Among the thylakoid lipids, the proportion of MGDG increased rapidly since the beginning 
of germination, while the concentration of DGDG, PG and SQDG remained constant (Fig. 6b). Several studies carried out with Arabidopsis mutants containing significantly less MGDG have demonstrated that this lipid is essential for the proper organization of the thylakoid membranes, for the optimal PS activity and for the correct function of the photoprotection mechanisms (Kobayashi et al., 2007; Aronsson, 2008; Aronsson et al., 2008). On other hand, a decrease in the concentration of MGDG is a common response of plants to different kind of dehydration stress like salt, freezing or desiccation (Moellering et al., 2010; Gasulla et al., 2013; Wang et al., 2016). MGDG are cone-shaped lipids and trend to form inverted hexagonal II structures during water loss destabilizing the thylakoid membranes and causing their fusion or fission (Sprague, 1987; Webb and Green, 1991). The chloroplast of the spores also contained a relative high proportion of oligogalactolipids, especially TGDG. These galactolipids have been associated with the acquisition of DT because of their large polar-head that can enhance the repulsive forces between membranes avoiding their fusion when the intracellular water is lost (Gasulla et al., 2013). In vascular plants growing under optimal conditions oligogalactolipids are completely degraded, like in $O$. regalis gametophyes, because their presence might result in inappropriate repulsive forces between neighboring membranes affecting the photosynthesis activity (to be demonstrated) (Chow et al., 2005). Thus, the accumulation of MGDG and the degradation of TGDG in $O$. regalis during the gametophyte growth might be beneficial for improving the photosynthesis activity but, on the contrary, might compromise its survival in case of dehydration. In parallel, there was a decrease in the concentration of $\mathrm{PI}$ in the extraplastidial membranes during germination. The accumulation of PI has been related with the acquisition of desiccationtolerance in photosynthetic organisms (Gasulla et al., 2013; Gasulla et al., 2016). Due to their sugar alcohol polar-head PI could play the same protective role that oligogalactolipids do in thylakoids, i.e., avoiding the fusion of extraplastidial membranes in dried cells. Consequently, the gradual decrease of PI concentration in $\mathrm{O}$. regalis during germination might also reduce its resistance to desiccation.

The most abundant lipid in $O$. regalis spores was TAG but after $72 \mathrm{~h}$ of germination it started to be degraded and gametophytes only contained about 6 $\%$ of the initial concentration. In plants, TAG is accumulated forming lipid droplets, 
like those observed in O. regalis spores (Ballesteros et al, 2011). When needed, the cytosolic lipase SUGARDEPENDENT1 (SDP1) hydrolyzes the TAG into DAG and free fatty acids (Kelly et al., 2013), which are broken down via $\beta$-oxidation in the glyoxisome into acetyl-CoA, a key metabolite for energy production via mitochondrial respiration and for the synthesis of carbohydrates (Graham, 2008). The mobilization and sequential hydrolysis of storage reserves has been found to be crucial in both chlorophyllous and non-chlorophyllous spores for the spore germination (DeMaggio and Stetler, 1985; Raghavan, 1992). The important decay of PC concentration after germination may also be related with the mobilization of the TAG reservoir. PC is the main phospholipid in the glyoxisomes and lipid bodies membranes, representing $58 \%$ and $37 \%$, respectively (Moreau et al., 1998). Thus a reduction in the size and number of the lipid droplets, and probably the associated glyoxysomes, might explain the decline in PC abundance during the development of $O$. regalis gametophytes. Another indirect consequence of TAG degradation may be the accumulation of PA. The DAG derived from SP1-mediated TAG hydrolysis can be phosphorylated by DAG kinase to synthesize PA (Katagiri et al., 1996).

The spores of $O$. regalis showed a higher degree of lipid saturation than gametophytes, being the $\mathrm{DBI}$ of polar lipids $35 \%$ higher in gametophytes than in the spores. The proportion of polyunsaturated fatty acids in membranes has been negatively related with the longevity of dried plant propagules (Hoekstra, 2005). Double bonds of fatty acid can be easily oxidized by free radicals because of their reactive hydrogen atoms (North et al., 1994). Lipid peroxidation can result in membrane disruption or the oxidation can be propagated to other lipids or enzymes (Stark, 2005). In organisms containing chloroplast the risk of generation of free radicals is enhanced during drying in presence of illumination. Thus, in $O$. regalis, the low proportion of poly-unsaturated fatty acids could reduce the possibility of membrane damages caused by oxidation. Another advantage of having polar lipids with highly saturated acyl chains is that they decrease the fluidity of the membranes limiting the mobility of their components. Avoiding the access of enzymes -especially those with hydrolytic activity, like PLD- to the membranes is critical for the protection of membranes during desiccation (Chen et al., 2018). 


\section{Concluding remarks}

In the fate of climate change and the compromise with food security, the community of plant researchers have the duty to develop a new generation of stress tolerant crops. Resurrection plants have been considered for a long time as a promising resource for biotechnological applications (Zhang and Bartels 2017). However we are still far from understanding the intricate network of mechanisms involved in plant desiccation tolerance. With the present work we propose a new model for the study of these mechanisms in vascular plants: the chlorophyllous fern spores. With the advantage of using a unicellular tracheophyte system bearing fully developed chloroplasts, here we show the importance of thylakoid lipid remodelling and photochemical processes in the fast transition from a desiccation-tolerant to a desiccation-sensitive state in a same single cell. But this is just one among the many aspects of plant stress physiology that can be unravelled by the use of this unique structure.

\section{Acknowledgements}

This work was funded by (i) the Basque Government (research project UPV/EHU IT-1018-16; and Predoctoral Fellowship to MLP); (ii) the Spanish Ministry of Economy and Competitiveness (MINECO) and the ERDF (FEDER) (research project CTM2014-53902-C2-2-P, and Juan de la Cierva-Incorporation fellowship IJCI-2014-22489 to BFM). Lipids were measured by the lipidomics platform at the IMBIO, University of Bonn (Germany) 


\section{References}

Alpert, P., 2005. The limits and frontiers of desiccation-tolerant life. Int Comp Biol 45, 685-695

Aronsson, H., Schottler, MA., Kelly, AA., Sundqvist, C., Dormann, P., Karim, S., Jarvis, P., 2008. Monogalactosyldiacylglycerol deficiency in Arabidopsis affects pigment composition in the prolamellar body and impairs thylakoid membrane energization and photoprotection in leaves. Plant Physiol 148, 580-592.

Aronsson, H., 2008. The galactolipid monogalactosyldiacylglycerol (MGDG) contributes to photosynthesis-related processes in Arabidopsis thaliana. Plant Signal Behav 3, 1093-1095.

Ballesteros, D., Estrelles, E., Walters, C., Ibars, A.M., 2011. Effect of Storage Temperature on Green Spore Longevity for the Ferns Equisetum Ramosissimum and Osmunda regalis. Cryo Letters 32(2), 89-98.

Ballesteros, D., Hill, L.M., Walters, C., 2017. Variation of desiccation tolerance and longevity in fern spores. J Plant Physiol 211, 53-62

Ballesteros, D., Narayan, S., Varghese, B., Sershen (2018) Photo-oxidation modulates green fern spore longevity during dry storage. Plant Cell Tissue Organ Cult 133, 165.

Banks, J.A., 1999. Gametophyte development in ferns. Annu Rev Plant Biol 50, 163-186

Bewley, J.D., and Krochko, J.E., 1982. Desiccation-tolerance. In O. L. Lange, P. S. Nobel, C. B. Osmond, and H. Ziegler [eds.], Encyclopedia of plant physiology. Springer-Verlag, Berlin. vol. 12B, 57-107. 
Bilger, W., 2014. Desiccation-induced quenching of chlorophyll fluorescence in cryptogams. In Demmig-Adams B, Garab G, Adams III W (eds): Nonphotochemical quenching and energy dissipation in plants, algae and cyanobacteria. pp. 409-443. Springer, Dordrecht.

Catalá, M., Esteban, M., Rodríguez-Gil, J.L., Quintanilla, L.G., 2009. Development of a naturally miniaturised testing method based on the mitochondrial activity of fern spores: a new higher plant bioassay. Chemosphere 77, 983-988

Chen, H., Yu, X., Zhang, X., Yang, L., Huang, X., Zhang, J., Pritchard, H.W., Li, W., 2018. Phospholipase Da1-mediated phosphatidic acid change is a key determinant of desiccation-induced viability loss in seeds. Plant Cell Environ $41,50-63$

Chow, W.S., Kim, E.H., Horton, P., Anderson, J.M., 2005. Granal stacking of thylakoid membranes in higher plant chloroplasts: the physicochemical forces at work and the functional consequences that ensue, Photochem Photobiol Sci 4, 1081-1090.

Dall'Osto, L., Cazzaniga, S., Havaux, M., Bassi, R., 2010. Enhanced photoprotection by protein-bound vs free xanthophyll pools: A comparative analysis of chlorophyll b and xanthophyll biosynthesis mutants. Mol Plant 3, 576-593.

DeMaggio, A. E., and Stetler, D. A. 1985. Mobilization of storage reserves during fern spore germination. Proc R Soc Edinburgh 86B, 195-202

Demmig-Adams, B., 1990. Carotenoids and photoprotection of plants: a role for the xanthophyll zeaxanthin. Biochim Biophys Acta 1020, 1-24

Demmig-Adams, B., Adams, W.W., Logan, BA., Verhoeven, A.S., 1995. Xanthophyll cycle-dependent energy dissipation and flexible photosystem II efficiency in plants acclimated to light stress. Aust J Plant Physiol 22, 249-260 
Dörmann, P., 2013. Galactolipids in plant membranes. Encyclopedia of Life Sciences, John Wiley \& Sons Article A0024673, vs. 2.0, pp. 1-7

Dyer, A.F., 1979. The experimental biology of ferns. Academic, London

Esteban, R., Barrutia, O., Artetxe, U., Fernández-Marín, B., Hernández, A., García-Plazaola, J.I., 2015. Internal and external factors affecting photosynthetic pigment composition in plants: A meta-analytical approach. New Phytol 206(1), 268-280.

Farrant, J., 2007. Mechanisms of desiccation tolerance in angiosperm resurrection plants. In Plant desiccation tolerance, eds. M.A. Jenks, A.J. Wood, pp. 51-90. lowa: Blackwell Publishing

Fernández-Marín, B., Balaguer, L., Esteban, R., Becerril, J.M., GarcíaPlazaola, J.I., 2009. Dark induction of the photoprotective xanthophyll cycle in response to dehydration. J Plant Physiol 166,1734-1744

Fernández-Marín, B., Becerril, J.M., García-Plazaola, J.I., 2010. Unravelling the roles of desiccation-induced xanthophyll cycle activity in darkness: a case study in Lobaria pulmonaria. Planta 231, 1335-1342

Fernández-Marín, B., Míguez, F., Becerril, J.M., García-Plazaola, J.I., 2011. Dehydration-mediated activation of the xanthophyll cycle in darkness: is it related to desiccation tolerance? Planta $243,579-588$

Fernández-Marín, B., Kranner, I., San Sebastián, M., Artetxe, U., Laza, J.M., Vilas, J.L., Pritchard, H.W., Nadajaran, J., Míguez, F., Becerril, J., GarcíaPlazaola, J.I., 2013. Evidence for the absence of enzymatic reactions in the glassy state. A case study of xanthophyll cycle pigments in the desiccationtolerant moss Syntrichia ruralis. J Exp Bot 64, 3033-3043 
Fernández-Marín, B., Holzinger, A., Garcia-Plazaola, J.I., 2016. Photosynthetic strategies of desiccation-tolerant organisms. In: Pessarakli M (ed) Handbook of photosynthesis, pp 719-737. 3rd Edn, CRC Press, Boca Raton, FL.

Fernández-Marín, B., Neuner, G., Kuprian, E., Laza, J.M., García-Plazaola, J.I., Verhoeven, A., 2018. First evidence of freezing tolerance in a resurrection plant: insights into molecular mobility and zeaxanthin synthesis in the dark. Physiol Plant. doi10.1111:ppl.12694

Farrar, D.R., Dassler, C., Watkins, J.E., Skelton, C., 2008. Gametophyte ecology," in Biology and Evolution of Ferns and Lycophytes, eds T. Ranker and C. Haufler (New York, NY: Cambridge University Press), 222-251

Gaff, D.F., 1977. Desiccation tolerant vascular plants of Southern Africa. Oecol 31, 95-109.

Gaff, D.F., Oliver, M., 2013. The evolution of desiccation tolerance in angiosperm plants: a rare yet common phenomenon. Funct Plant Biol 40, $315-328$

García-Plazaola, J.I., and Becerri,I J.M., 1999. A rapid HPLC method to measure lipophilic antioxidants in stressed plants: simultaneous determination of carotenoids and tocopherols. Phytochem Analysis 10, 307313.

García-Plazaola, J.I., and Becerril J.M., 2001. Seasonal changes in photosynthetic pigments and antioxidants in beech (Fagus sylvatica) in a Mediterranean climate: implications for tree decline diagnosis. Aust $\mathrm{J}$ Plant Physiol 28, 225-232.

García-Plazaola, J.I., Esteban, R., Fernández-Marín, B., Kranner, I., PorcarCastell, A., 2012. Thermal energy dissipation and xanthophyll cycles beyond the Arabidopsis model. Photosynth Res 113, 89-103 
Gasulla, F., de Nova, P.G., Esteban-Carrasco, A., Zapata, J.M., Barreno, E., Guéra, A., 2009. Dehydration rate and time of desiccation affect recovery of the lichen alga Trebouxia erici: alternative and classical protective mechanisms. Planta 23, 195-208

Gasulla, F., Vom Dorp, K., Dombrink, I., Zähringer, U., Gisch, N., Dörmann, P., Bartels, D., 2013. The role of lipid metabolism in the acquisition of desiccation tolerance in Craterostigma plantagineum: a comparative approach. Plant J 75, 726-741.

Gasulla, F., Barreno, E., Parages, M. L., Cámara, J., Jiménez, C., Dörmann, P., and Bartels, D,. 2016. The role of phospholipase D and MAPK signaling cascades in the adaption of lichen microalgae to desiccation: changes in membrane lipids and phosphoproteome. Plant Cell Physiol 57, 1908-1920

Georgieva, K., Maslenkova, L., Peeva, V., Markovska, Y., Stefanov, D., Tuba, Z., 2005. Comparative study on the changes in photosynthetic activity of the homoiochlorophyllous desiccation-tolerant Haberlea rhodopensis and desiccation-sensitive spinach leaves during desiccation and rehydration. Photosynth Res 85, 191-203

Georgieva, K., Ivanova, A., Doncheva, S., Petkova, S., Stefanov, D., P.li, E., Tuba, Z. 2011. Fatty acid content during reconstitution of the photosynthetic apparatus in the air-dried leaves of Xerophyta scabrida after rehydration. Biol Plant 55, 581-585.

Graham, I.A., 2008. Seed storage oil mobilization. Annu Rev Plant Biol 59, $115-142$

Havaux, M., García-plazaola, J.I., 2014. Beyond non-photochemical fluorescence quenching: the overlapping antioxidant functions of zeaxanthin and tocopherols, in: Demmig-Adams, B., Garab, G., Adams III, W., Govindjee 
(Eds.), Non-Photochemical Quenching and Energy Dissipation in Plants, Algae and Cyanobacteria pp. 583-603. Springer, Dordrecht, Dordrecht.

Heber, U., Lange, O.L., Shuvalov, V.A., 2006. Conservation and dissipation of light energy as complementary processes: homoiohydric and poikilohydric autotrophs. J Exp Bot 57, 1211-1223

Hoekstra, F.A., and Golovina, E.A., 1999. Membrane behavior during dehydration: implications for desiccation tolerance. Russ J Plant Physl 46, 295-306

Hoekstra, F.A., Golovina, E.A. and Buitink, J., 2001. Mechanisms of plant desiccation tolerance. Trends Plant Sci 6, 431-438.

Hoekstra, F.A., 2005. Differential Longevities in Desiccated Anhydrobiotic Plant Systems Integr Comp Biol 45, 725-733

Kappen, L., Valladares, F., 2007. Opportunistic Growth and Desiccation Tolerance: The Ecological Success of Poikilohydrous Autotrophs. In: Pugnaire $\mathrm{F}$ and Valladares $\mathrm{F}$ (eds) Functional Plant Ecology. Taylor and Francis, New York.

Katagiri, T., Mizoguchi, T., Shinozaki, K., 1996. Molecular cloning of a cDNA encoding diacylglycerol kinase (DGK) in Arabidopsis thaliana. Plant Mol Biol $30,647-653$

Kelly, A.A., van Erp, H., Quettier, A.L., Shaw, E., Menard, G., Kurup, S., Eastmond, P.J., 2013. The sugar-dependent1 lipase limits triacylglycerol accumulation in vegetative tissues of Arabidopsis. Plant Physiol 162, 12821289

Kobayashi, K., Kondo, M., Fukuda, H., Nishimura, M., Ohta, H., 2007. Galactolipid synthesis in chloroplast inner envelope is essential for proper 
thylakoid biogenesis, photosynthesis, and embryogenesis, Proc Natl Acad Sci USA 104, 17216-17221.

Koonjul, P.K., Brandt, W.F., Lindsey, G.G., Farrant, J.M., 2000. Isolation and characterisation of chloroplasts from Myrothamnus flabellifolius. J Plant Physiol 156, 584-594.

Kranner, I., Beckett, RP., Wornik, S., Zorn, M., Pfeifhofer, H.W., 2002. Revival of a resurrection plant correlates with its antioxidant status. Plant J 31: 13-24

López-Pozo M., Fernández-Marín B., García-Plazaola J.I., Ballesteros D. (2018) Desiccation Tolerance in Ferns: From the Unicellular Spore to the Multi-tissular Sporophyte. In: Fernández H. (eds) Current Advances in Fern Research. Springer, Cham

Mikula, A., Tomiczak, K., Makowski, D., Niedzielski, M., Rybczyński, J.J., 2015. The effect of moisture content and temperature on spore aging in Osmunda regalis. Acta Physiol Plant 37,229

Moellering, E.R., Muthan, B. and Benning, C., 2010. Freezing tolerance in plants requires lipid remodeling at the outer chloroplast membrane. Science 330, 226-228.

Moreau, P., Bessoule, J.J., Mongrand, S., Testet, E., Vincent, P., Cassagne, C., 1998. Lipid trafficking in plant cells. Prog Lipid Res 37, 371-391

North, J. A., Spector, A. A., and Buettner, G. R., 1994. Cell fatty acid composition affects free radical formation during lipid peroxidation. Am $\mathrm{J}$ Physiol 267, C177-C188.

Oliver, M.J., Bewley, J.D., 1997. Desiccation tolerance in plant tissues. A mechanistic overview. Hortic Rev 18, 171-214 
Oliver, M.J., Tuba, Z., Mishler, B.D., 2000. The evolution of vegetative desiccation tolerance in land plants. Plant Ecol 151, 85-100.

Pence, VC., 2000. Survival of chlorophyllous and non-chlorophyllous fern spores through exposure to liquid nitrogen. Amer Fern J 90, 119-126

Pence, V.C., 2008 in (ed) BM Reed, Plant Cryopreservation: A Practical Guide pp 117-140.Springer, New York.

Pressel, S., Duckett., J.G., 2010. Cytological insights into the desiccation biology of a model system: moss protonemata. New Phytol 185, 944-963.

Proctor, M.C.F., 2003. Experiments on the effect of different intensities of desiccation on bryophyte survival, using chlorophyll fluorescence as an index of recovery. J Bryol 25, 215-224.

Quintanilla, L.G., Pajarón, S., Pangua, E., Amigo, J. 2000. Effect of temperature on germination in Northern most populations of Culcita macrocarpa and Woodwardia radicans. Plant biol 2: 612-617.

Raghavan, V., 1992. Germination of fern spores. Am Scientist 80, 176-185

Rakic, T., Gajic, G., Lazarevic, M., Stevanovic, B., 2015. Effects of different light intensities, $\mathrm{CO} 2$ concentrations, temperatures and drought stress on photosynthetic activity in two paleoendemic resurrection plant species Ramonda serbica and R. nathaliae. Environ Exp Bot 109, 63-72

Roughan, P.G., Slack, C.R. and Holland, R., 1978. Generation of phospholipid artefacts during extraction of developing soybean seeds with methanolic solvents. Lipids 13, 497-503.

Salmi, M.L., Bushart, T., Roux, S.J., 2011. Cellular, molecular, and genetic changes during the development of Ceratopteris richardii gametophytes. In: 
Working with Ferns. Eds: Fernández H, Revilla MA, Kumar A. Springer Science+Business Media.

Smirnoff, N., 1993. The role of active oxygen in the response of plants to water deficit and desiccation. New Phytol, 125, 27-58.

Sprague, S.G., 1987. Structural and functional consequences of galactolipids on thylakoid membrane organization. J Bioenerg Biomembr 19, 691-703.

Stark, G., 2005. Functional consequences of oxidative membrane damage. J Membr Biol 205, 1-16.

Stark, L.R., 2017. Ecology of desiccation tolerance in bryophytes: a conceptual framework and methodology. Bryol 120, 130-165

Sundue, M.A., Vasco, A., Moran, RC., 2011. Cryptochlorophyllous spores in ferns: nongreen spores that contain chlorophyll. Int J Plant Sci 172, 11101119

Suo, J., Zhao, Q., Zhang, Z., Chen, S., Cao, J., Liu, G., Wei, X., Wang, T., Yang, C., Dai, S., 2015. Cytological and proteomic analyses of Osmunda cinnamomea germinating spores reveal characteristics of fern spore germination and rhizoid tip growth. Am Soc Biochem Mol Biol 14, 2510-2534

Takano, A., and Inoue, H., 1992. Protease of chloroplasts during germination in green spores of the fern Osmunda japonica. Photosynth Res 3, 205-208

Verhoeven, A., García-Plazaola, J.I., Fernández-Marín, B., 2018. Shared mechanisms of photoprotection in photosynthetic organisms tolerant to desiccation or to low temperature. Environ Exp Bot doi.org/10.1016/j.envexpbot.2017.09.012 
Wang, K., Hersh, H.L., and Benning, C., 2016. SENSITIVE TO FREEZING2 Aides in resilience to salt and drought in freezing-sensitive tomato. Plant Physiol 172, 1432-1442.

Webb, M.S., and Green, B.R., 1991. Biochemical and biophysical properties of thylakoid acyl lipids. Biochim Biophys Acta 1060, 133-158. 


\section{Supplementary material}

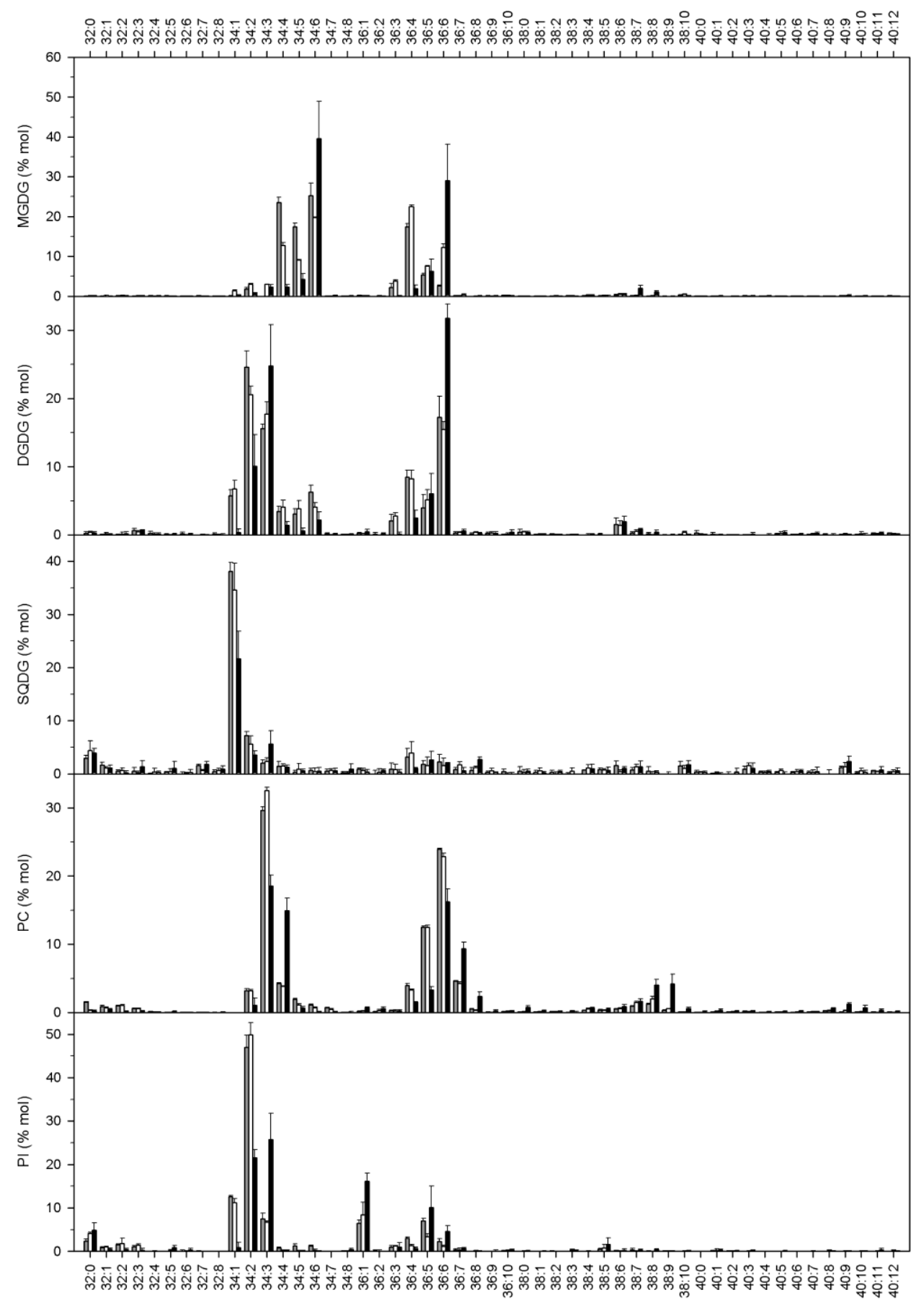

Figure S1. Molar percentages of molecular species of each major polar lipids measured in Osmunda regalis in control state (grey bars), in spores after 3 days of light and hydration (white bars), and in 6 months gametophytes (black bars). MGDG, monogalactosyldiacylglycerol; DGDG, digalactosyldiacylglycerol; SQDG, sulfoquinovosyldiaylglycerol; PC, phosphatidylcholine; PI, phosphatidylinositol. Values are means \pm SE $(n=3)$ 


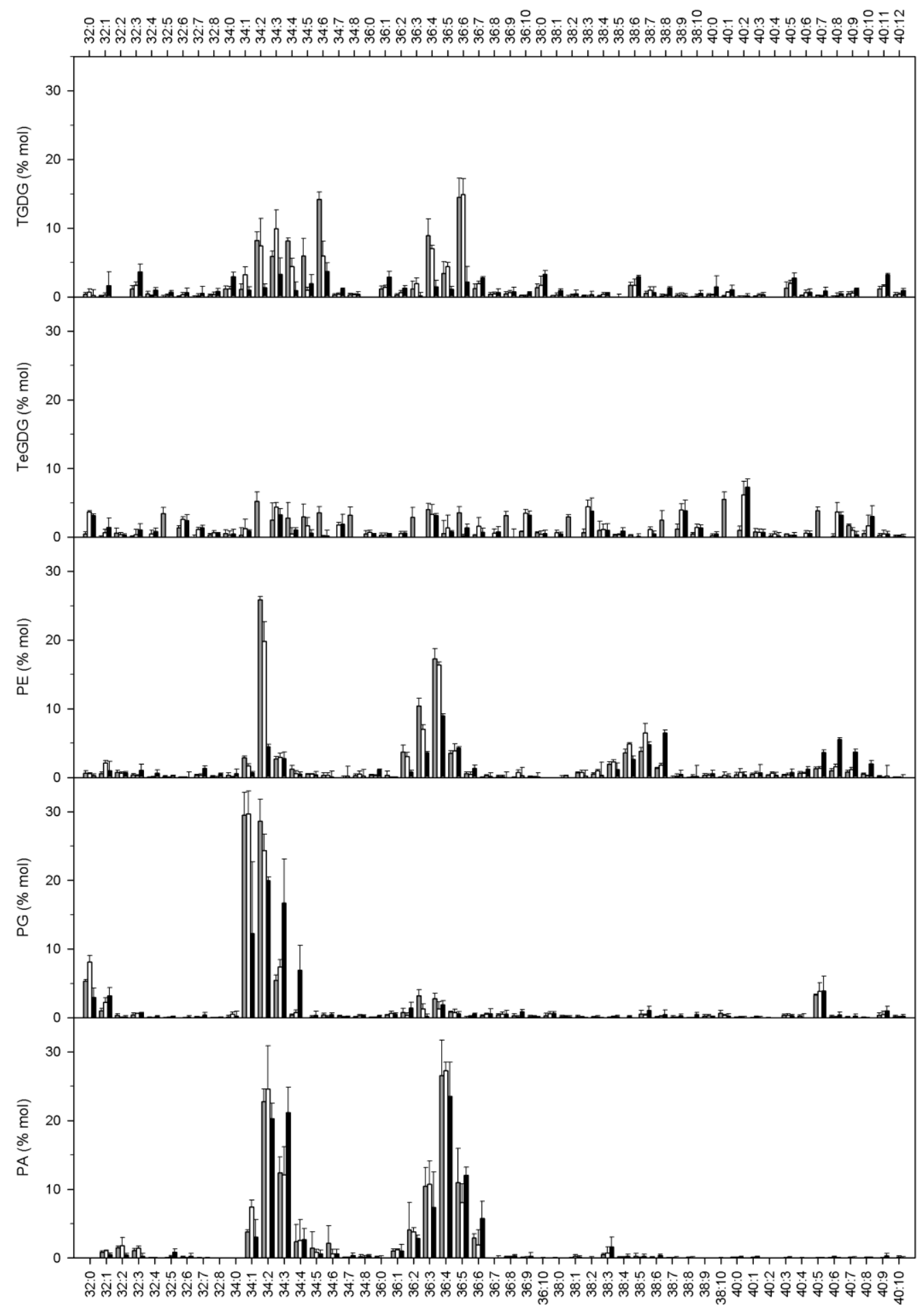

Figure S2. Molar percentages of molecular species of each minor polar lipids measured in Osmunda regalis in control state (grey bars), in spores after 3 days of light and hydration (white bars), and in 6 months gametophytes (black bars). TGDG, trigalactosyldiacylglycerol; TeGDG, tetragalactosyldiacylglycerol; PE, phosphatidylethanolamine; PG, phosphatidylglycerol; PA, phosphatidic acid. Values are means \pm SE $(n=3)$ 

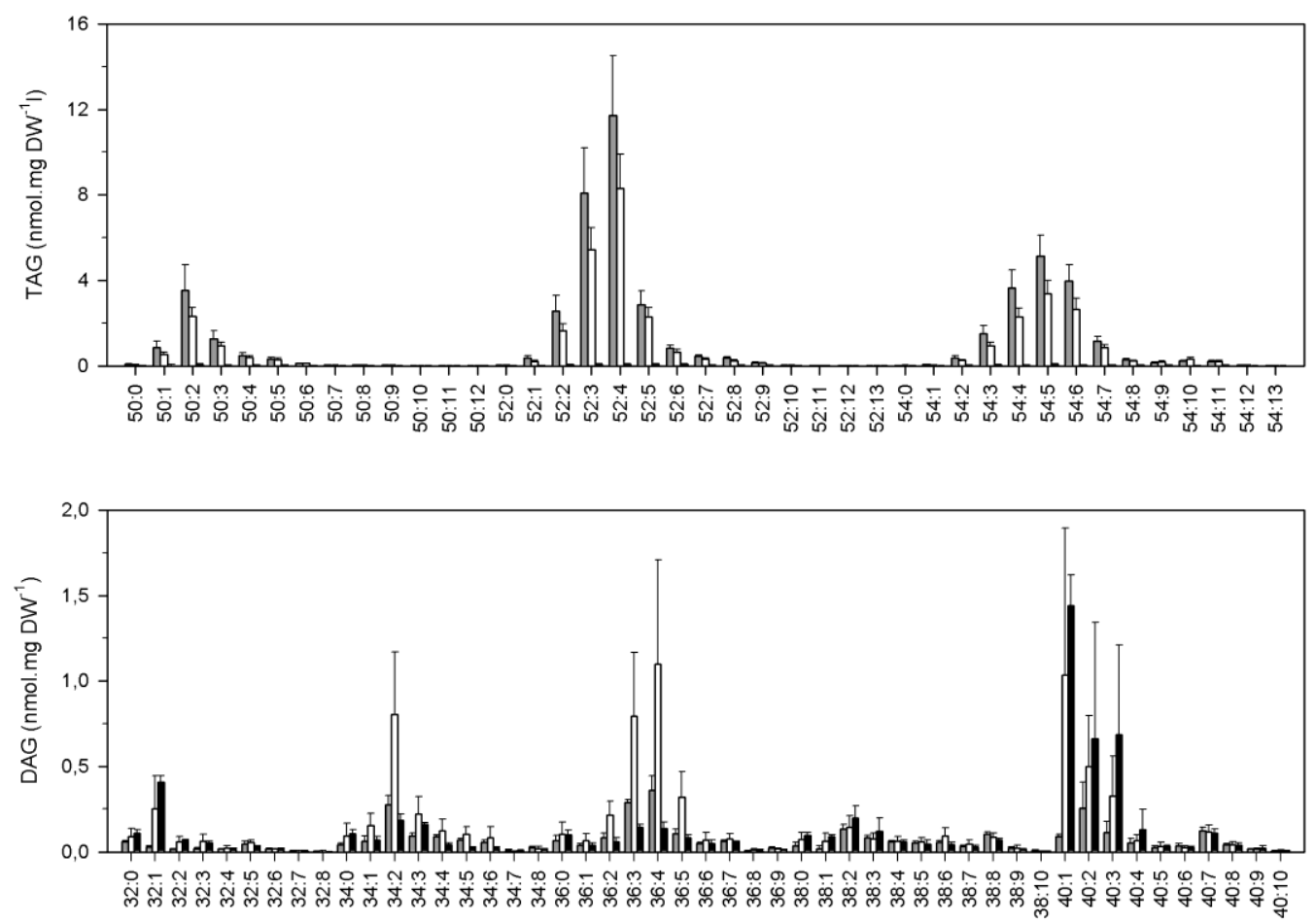

Figure S3. Molar percentages of molecular species of each neutral polar lipids measured in $O$. regalis in control state (grey bars), in spores after 3 days of light and hydration (white bars), and in 6 months gametophytes (black bars). TAG, triacylglycerol; DAG, diacylglycerol. Values are means $\pm \operatorname{SE}(n=3)$. 